\title{
Rembrandt's 'Saul and David' (c. 1652): use of multiple types of smalt evidenced by means of non-destructive imaging
}

\author{
K. Janssens, ${ }^{a}$ G. Van Der Snickt, ${ }^{a}$ M. Alfeld, ${ }^{a, b}$ P. Noble, ${ }^{c, d}$ A. van Loon, ${ }^{c, e}$ J. Delaney, ${ }^{f}$ D. Conover, ${ }^{f}$
}

J. Zeibel ${ }^{9}$ and J. Dik

a University of Antwerp, Belgium

b Université Pierre \& Marie Curie, Paris

c Royal Picture Gallery Mauritshuis, The Hague, The Netherlands

d Rijksmuseum, Amsterdam, The Netherlands

e Delft University of Technology, The Netherlands

f National Gallery of Art, Washington DC, USA

g Night Vision and Electronic Sensors Directorate, Ft. Belvoir, Virginia, USA

\section{Abstract}

The painting Saul and David, considered to date from c. 1652 and previously attributed to Rembrandt van Rijn and/or his studio, is a complex work of art that has been recently subjected to intensive investigation and conservation treatment. The goal of the research was to give insight into the painting's physical construction and condition in preparation for conservation treatment. It was also anticipated that analysis would shed light on authenticity questions and Rembrandt's role in the creation of the painting. The painting depicts the Old Testament figures of King Saul and David. At left is Saul, seated, holding a spear and wiping a tear from his eye with a curtain. David kneels before him at the right playing his harp. In the past, the large sections with the life-size figures were cut apart and later reassembled. A third piece of canvas was added to replace a missing piece of canvas above the head of David. As part of the investigation into the authenticity of the curtain area, a number of paint micro samples were examined with LM and SEM-EDX. Given that the earth, smalt and lake pigments used in the painting could not be imaged with traditional imaging techniques, the entire painting was also examined with state of the art non-destructive imaging techniques. Special attention was devoted to the presence of cobalt-containing materials, specifically the blue glass pigment smalt considered characteristic for the late Rembrandt. A combination of quantitative electron microprobe analysis and macroscopic X-ray fluorescence scanning revealed that three types of cobalt-containing materials are present in the painting. The first type is a cobalt drier that was found in the overpaint used to cover up the canvas inset and the joins that were added in the $19^{\text {th }}$ century. The other two Co-containing materials are part of the original paint used by Rembrandt and comprise two varieties of smalt, a K-rich glass pigment that derives its grey-blue color by doping with Co-ions. Smalt paint with a higher $\mathrm{Ni}$ content ( $\mathrm{NiO}: \mathrm{CoO}$ ratio of around 1:4) was used to depict the blue stripes in Saul's colourful turban, while smalt with a lower Ni content was employed ( $\mathrm{NiO}: \mathrm{CoO}$ ratio of around 1:5) for the broad expanses of Saul's garments. The presence of two types of smalt not only supports the recent re-attribution of the painting to Rembrandt, but also that the picture was painted in two phases. Saul's dark red garment is painted in a rough, "loose" manner and the now discolored smalt-rich layer was found to have been partially removed during a past restoration treatment/s. In contrast, the blue-green smalt in the turban is much better preserved and provides a colorful accent. While the use of different types of smalt in a Rembrandt painting has been previously identified using quantitative EDX analysis of paint cross-sections, to the best of our knowledge this is the first time such a distinction has been observed in a $17^{\text {th }}$-century painting using non-destructive imaging 
techniques. In addition to the XRF-based non-invasive elemental mapping, hyperspectral imaging in the visual to near-infrared (VNIR) region was also carried out.

Keywords: $17^{\text {th }}$-century painting, Rembrandt, smalt, X-ray fluorescence scanning, hyperspectral imaging, non-destructive imaging, Saul and David

\section{Introduction}

The painting Saul and David (Fig. 1), part of the collection of the Royal Picture Gallery Mauritshuis in The Hague, dated to c. 1652, shows two figures against a dark background. At left is Saul, seated, holding a spear and wiping a tear from his eye with a curtain. David kneels before him at the right playing his harp. The subject of Saul and David is usually considered to be the moment before the frenzy of King Saul, which caused him to hurl his spear at David (I Samuel 18: 9-11). ${ }^{1}$ At some point in the past, the figures of Saul and David were cut apart, and later rejoined (before 1869), at the same time adding a large square above David's head to replace a piece of missing canvas. As seen in Fig. $1 \mathrm{~b}$, this upper right section of canvas was found to originate from one of the many copies made after a painting by Anthony Van Dyck, depicting a portrait of Isabella Clara Eugenia in the habit of the Poor Clares. ${ }^{2}$ Narrow strips were also added to the upper, bottom and right edges. Thus, the painting now consists of some 10 separate pieces of canvas (15 if one considers that the strips along the edges are made up of composite pieces), while a narrow strip of the original canvas is missing along the vertical join between the figures of Saul and David. 3 The painting was acquired in 1898 by the then Mauritshuis director, Abraham Bredius who bequeathed it to the Mauritshuis in 1946. Full details on the painting's provenance are found in Ref. 4 .

This painting has only recently been welcomed back into the catalogue of Rembrandt's works.5,6 Doubts had already been raised in the 19th century about Rembrandt's authorship and in 1969 the work was dismissed from Rembrandt's oeuvre by a leading Rembrandt scholar.7 Prior to 1969, however, the picture was always generally regarded as one of Rembrandt's greatest paintings. ${ }^{8}$ During its recent study and conservation treatment, new insights have been gained about the stylistic and material aspects of the painting. This study supports the notion already proposed in 1978 by De Vries at al. that two stages in the painting process can be distinguished, although the picture is now considered to have been begun somewhat earlier. ${ }^{9}$ The painting was started in a more colorful style characterized by greater detailing and smoother handling of the paint. In contrast, the adjustments made to the painting during the second stage are painted very loosely. ${ }^{10}$ Certain passages are particularly difficult to interpret, for instance in the garment of Saul at the lower left, where thick brushstrokes of red oxide paint have been left exposed in a very awkward manner. Also remarkable is the extensive application of smalt. Smalt is a pigment that ranges in color from grey to blue and is obtained by grinding appropriately colored glass into a fine powder; $\mathrm{K}_{2} \mathrm{O}$-rich glass can be colored intensely blue by adding $\mathrm{CO}^{2+}$-salts to the melt. ${ }^{11}$ It would seem that Rembrandt was experimenting with the use of smalt in this second phase, since it was found over much of the painting, in a mixture with a little earth pigment and organic yellow lake. The extensive use of smalt especially in mixtures with bone black, lakes and earth pigments is considered typical of Rembrandt's late painting technique, not only to create coloristic effects, but also for its drying properties and to give bulk and texture to the paint. ${ }^{12}$ 
In order to learn more about the authenticity and condition of the curtain, in 2011 , the central area/background between the two figures of Saul and David, was investigated by means of Macroscopic X-ray fluorescence scanning (MA-XRF - see Note 4 in Ref. 4). Light microscopy (LM) and Scanning Electron Microscopy coupled to energy dispersive X-ray analysis (SEM-EDX) of paint samples was carried out prior to MA-XRF in 2009-2010. Cross-section analysis demonstrated that smalt was found only in the paint of the original curtain, not in the overpaint. The unique presence of smalt in the original paint suggested MA-XRF could provide the capability of imaging the original curtain without removing the later overpaint. The ensuing distribution maps of $\mathrm{Co}, \mathrm{Ni}$, As and $\mathrm{K}$, present in smalt, provided for the first time a clear image of the original curtain, hidden below the muddy overpaint and the brown varnish. With help of ratio plots (Co:Ni and $\mathrm{Co}: \mathrm{As}$ ) it was also possible to distinguish between $\mathrm{Co}$ in the smalt in the original paint and Co present as drier in the $19^{\text {th }}$-century overpaint. The ratio plots generated during the 2011 scanning of the painting also gave a first hint that possibly different types of smalts were used for the turban and the curtain and that this might be related to different stages of the painting process (see Note 10 in Ref. 4). ${ }^{13}$ These results encouraged us to record Co distribution maps of the entire painting $(125 \times 158 \mathrm{~cm})$. To assist in the correct interpretation of the painting's condition and the pigment-specific distributions that resulted from these noninvasive investigations, additional micro samples of the smalt layers were collected at select locations, and examined using quantitative SEM-EDX.

In addition to the XRF-based non-invasive elemental mapping, hyperspectral reflectance images in the visual to near-infrared (VNIR) region were recorded. By exploiting smalt's electronic transitions, especially in the near infrared, complementary maps to those obtained by means of XRF scanning were obtained.

We will now focus on whether different types of smalt can be distinguished in the painting. We will summarize the observations from the imaging data and discuss how the various imaging methods compare to one another. The consistency of the observations obtained via nondestructive imaging with information obtained from observations of the paint surface as well as microscopic analysis of a limited number of paint samples is also described. 

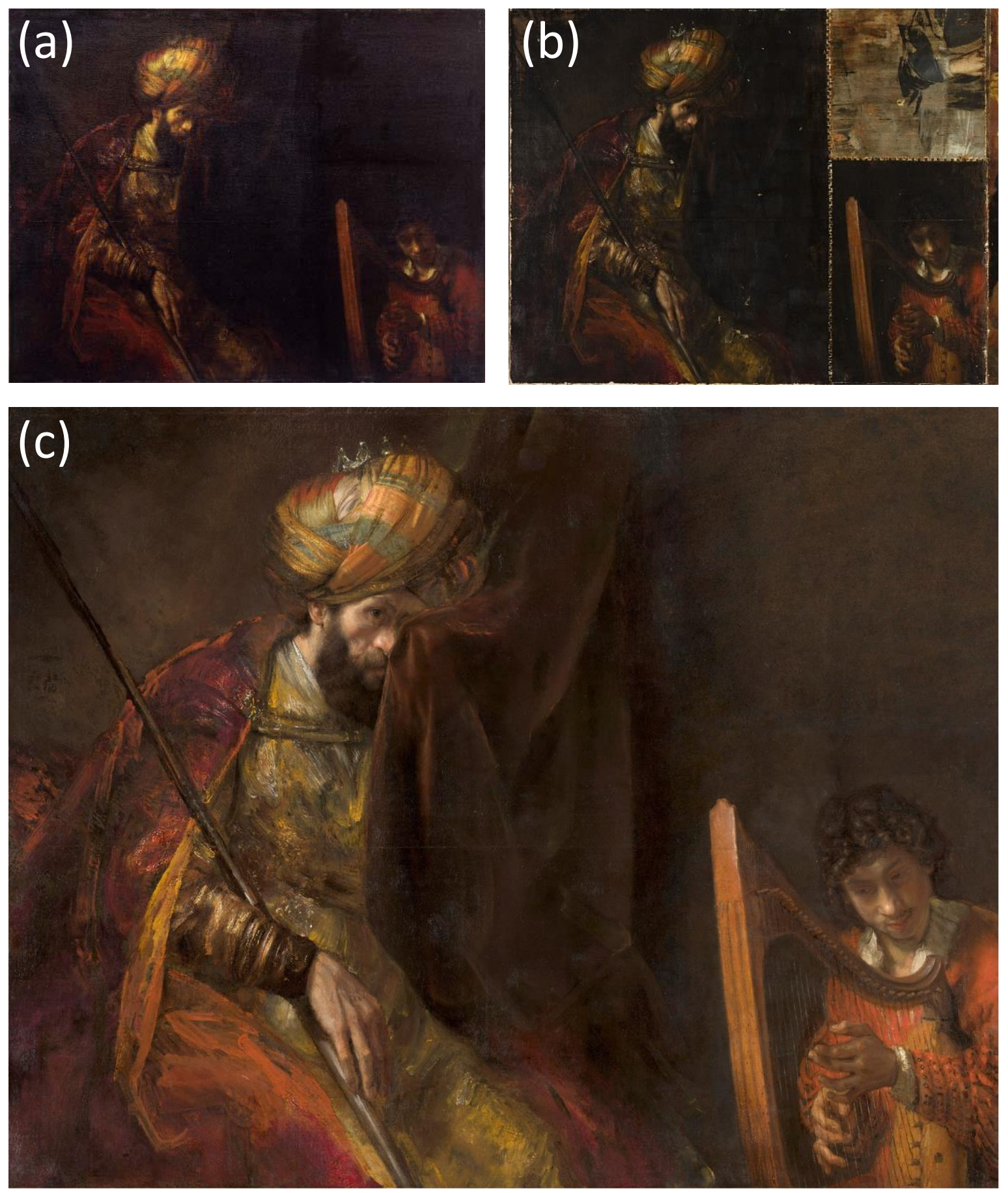

Figure 1. Rembrandt, 'Saul and David', c. 1652, $126 \times 158$ cm, Mauritshuis, inv. no. MH621/Bredius, no. 526), oil on canvas. (a) Before, (b) during and (c) after the recent conservation treatment. 


\section{Background information on smalt}

Smalt was commonly used as a pigment by artists between the 16th and 18th centuries. It often degrades in combination with an oil binder causing dramatic changes in the appearance of paintings. The tinting power of Co-salts in glass was already known to the Egyptians. The blue color stems from the fact that the chemical environment of $\mathrm{Co}^{2+}$ is tetrahedral; ${ }^{14}$ the positioning of $\mathrm{O}$-atoms around the $\mathrm{Co}$ causes its $3 \mathrm{~d}$ levels to split up so that photons in the visual range are absorbed. A doping of K-rich glass at the $0.5-10 \%$ level with Co gives rise to an intense blue color. Throughout the ages, glass was colored blue in this fashion using Co-rich ores originating from different geographic origins. In the $17^{\text {th }}$ century the most prominent European Co-source are the mines of the Erzgebirge in Central Germany which produce a sulfidic ore, rich in Co, but also in other bivalent transition elements such as $\mathrm{Fe}, \mathrm{Ni}$ and $\mathrm{As} .{ }^{15}$ In some cases, the ore also contains $\mathrm{Bi}$. Depending on the (chemical and thermal) purification treatment the ore is subjected to, Cooxide is produced that contains variable amounts of these pollutant elements. For example, ores that have been exposed to a more prolonged thermal treatment can be expected to have a lower abundance in volatile (minor) constituents such as As and Bi and possibly other elements. ${ }^{16}$ Due to the leaching-out of potassium from the glass (i.e., a gradual replacement of $\mathrm{K}^{+}$-ions in the glass network by $\mathrm{H}_{3} \mathrm{O}^{+}$-ions), the crystal field around the $\mathrm{Co}^{2+}$ ions may acquire a more octahedral symmetry, which causes the optical absorption behavior and thus the strong blue color to disappear. ${ }^{17,}{ }_{1}^{18}$ This discoloration phenomenon has been well documented ${ }^{19}$ and has taken place in many important works of art, especially in oil paintings of the $17^{\text {th }}$ century due to the widespread use of smalt in this period. It has been shown that the discoloration phenomenon is dependent on the glass composition ( $\mathrm{K}$-richer glass being more prone to leaching) ${ }^{20}$ but no relation between the origin of the smalt (as characterized by the (trace) element pattern of the cobalt ore) and its tendency towards discoloration has been observed.

Surprisingly, the fact that smalt frequently loses its blue color has only recently created doubts about the original appearance of some Rembrandt paintings, especially the late works that currently feature a fairly monochrome palette and where it is known that the pigment smalt is abundantly present. While previous analyses of paint cross sections or other non-invasive methods have identified the presence of smalt, to our knowledge there is only a handful of Rembrandt paintings where EDX analyses has proven that the smalt has undergone chemical alteration, causing it to lose much, if not all of the its original blue tinting power. 


\section{Experimental}

\section{Macro-XRF scanning}

The Saul and David painting was investigated in the Mauritshuis conservation studio on two occasions, in 2011 and 2013 using a self-built Macro-XRF scanner, capable of scanning areas of resp. $25 \times 50$ and $60 \times 60 \mathrm{~cm}^{2}$. In all scans, the lateral resolution was defined by a step size of 1 $\mathrm{mm}$. This prototype scanner consists of a $50 \mathrm{~W}$ molybdenum $X$-ray tube with a fixed polycapillary lens and four energy dispersive X-ray detectors mounted on a XZ-motor stage. ${ }^{21}{ }^{22}$ In 2011, only the central area was investigated (see Ref. 4 for details) using a dwell time per pixel that varied between 1.0 and $1.9 \mathrm{sec}$. During the 2013 scanning of the entire surface, the painting was scanned over a period of 3 days, at an average speed of $50 \mathrm{~cm}^{2} / \mathrm{hour}(0.2 \mathrm{sec} / \mathrm{pixel})$. A series of seven large scans measuring $60 \times 60 \mathrm{~cm}$ were performed as well as three smaller scans, to slightly extend the border of the investigated area. This resulted in elemental distribution images $1671 \times 1314$ pixels in size of $\mathrm{K}, \mathrm{Ca}, \mathrm{Cr}, \mathrm{Ba}, \mathrm{Cd}, \mathrm{Ti}, \mathrm{Mn}, \mathrm{Co}, \mathrm{Fe}, \mathrm{Ni}, \mathrm{Cu}, \mathrm{Zn}, \mathrm{Sr}, \mathrm{As}, \mathrm{Hg}, \mathrm{Pb}$ and $\mathrm{Bi}$. The acquired spectra were processed by the Datamuncher software ${ }^{23}, \mathrm{PyMCA}^{24}$ and other inhouse written software.

Hyperspectral imaging

A portable dual channel (Visible Near Infrared (VNIR) and Short Wave Infrared (SWIR)) whiskbroom scanning hyperspectral camera (Surface Optics Company, USA) was used for the reflectance imaging spectroscopy (RIS) measurements. Transmission mode images were recorded simultaneously in 720 wavelength bands spanning the spectral range of 400 to 1000 $\mathrm{nm}$ ( $1.4 \mathrm{~nm}$ sampling, VNIR) and 1000 to $2350 \mathrm{~nm}$ (3.4 nm sampling, SWIR). Each spectral image is 640 pixels along the slit of the spectrometer and 1080 pixels along the scan direction. The optical system consists of a whiskbroom scan mirror that directs light to a dichroic beam splitter that reflects the NIR and transmits the SWIR radiation. Each channel has its own fore optic and transmission grating spectrometer. The SWIR channel has a cooled (67K) 640 by 512 pixel InSb focal plane array (SBF178, Santa Barbara Focal Plane, US) with $20 \mu \mathrm{m}$ pixels. The VNIR channel utilizes an Electron Multiplying Charge Coupled Device (EM-CCD, EMV-VGA, Illunis). The whiskbroom scan mirror steps are synchronized with the focal plane image captures while scanning the painting. Integration times of 10 and $200 \mathrm{~ms}$ are used for the VNIR and SWIR channels respectively and the total scan time of the paintings was $5 \mathrm{~min}$. The painting was diffusely illuminated at $+/-45^{\circ}$ with six $50 \mathrm{~W}$ 4700K Solux lamps (Solux, NY). The VNIR and SWIR image cubes were corrected for dark offset and aligned in software. Image processing was done using ENVI 5 (Exelis, USA) and Matlab (2012b, MathWorks, MA). RIS maps were found using a normalized cross-correlation with endmember spectra derived from the cube using Matlab. 


\section{Light microscopy of paint micro-samples}

Paint micro samples were embedded in Technovit $2000 \mathrm{LC}$ mounting resin, a one-component methacrylate that polymerizes under visible blue light (Heraeus Kulzer $\mathrm{GmbH}$, Germany) and polished to expose the paint layer build-up. This was done with the assistance of a sample holder, on Micromesh sheets up to grade 12000 (Micro-Surface Finishing Products Inc., Wilton, lowa, USA). ${ }^{25}$ The embedded cross-sections were examined using a Leica DM2500 light microscope equipped with Leica DFC 490 digital camera (Mauritshuis, The Hague).

Scanning electron microscopy coupled with energy-dispersive $X$-ray analysis (SEM-EDX)

SEM-EDX analysis of the embedded samples was performed at the FOM Institute AMOLF in Amsterdam, using a FEI Verios 460 high-pressure electron microscope equipped with an Oxford EDX system. EDX spot analysis of the smalt pigment particles was done at $20 \mathrm{kV}$ acceleration voltage and $0.20 \mathrm{nA}$ beam current. The samples were gold coated $(3 \mathrm{~nm})$ on an SC7640 sputtercoater (Quorum Technologies, Newhaven, East Sussex, UK) prior to analysis in order to improve surface conductivity. 


\section{Results and discussion}

3.1 XRF scanning elemental distribution maps

In Fig. 2, a selected number of XRF distribution maps of the entire painting are shown. Only maps of elements $\mathrm{Co}, \mathrm{K}, \mathrm{Ni}$, As associated with the pigment smalt, are shown here. It is worth noting that these elemental maps were recorded prior to removal of the overpaint and darkened varnish layers that initially obscured the painting (Fig. $1 \mathrm{~A}$ ). The maps influenced the conservation treatment, providing essential information that lead to the decision to remove the overpaint (and varnish), as shown in the cleaned state image of the painting shown in Fig. $1 \mathrm{~B}$. From the Fe and Co distribution maps, it is immediately clear that the upper right canvas piece (marked $\gamma$ ) painted in a monochrome dark tone, does not show the same origin as the canvas sections of Saul and David (marked $\alpha$ and $\beta$ respectively in $\mathrm{Pb}-\mathrm{L}$ map). Both Co and Fe appear to be present throughout the $\gamma$ area at high abundance. The Co- and Fe-maps suggest that both the joins between the various sub-parts as well as the entire $y$-section were uniformly covered with an Fe and Co-containing overpaint.

Visual comparison of the $\mathrm{K}, \mathrm{Co}, \mathrm{Ni}$ and As maps of the $\alpha$-section reveal a similarity in their distribution, although not all details and highlights are exactly the same in all images. $\mathrm{K}$ is not only associated here with the use of smalt, but also with that of red lake (from alum or $\mathrm{KOH}$ added during its production). ${ }^{26}$ No significant Bi signals were recorded from this painting (as is the case for most other Rembrandt paintings examined with XRF scanning). Since the Fedistribution in the $\alpha$-section is quite different from those of the above-mentioned elements, we can infer that the Fe map is almost completely dominated by the earth pigment-containing areas, where the Fe concentration is much higher than in smalt (of the order of a few wt\%). Thus, it is not useful to employ the correlation between Co and Fe in the maps for the identification of different types of smalt.

The Co map of the $\alpha$-section demonstrates that smalt was used extensively in the areas of the turban, the curtain, Saul's garments and his chair. The patchy appearance at the left and bottom of the Co map, corresponding to areas of abraded and partially removed smalt-rich paint in Saul's cloak, which initially appears to have extended over the chair. The lighter (higher intensity) areas in the Co map correspond with the thicker/more intact smalt-rich paint. This was demonstrated by comparison with paint cross-sections from this region of the painting as well as surface examination of the painting with the stereo-microscope. Remains of a now darkened smalt-rich layer were found over much of Saul's garment and chair. Where the smalt layer has been (partially) removed, underlying bold brushstrokes of red oxide from the garment below became exposed. Paint cross-sections corresponding to the dark patchy areas in the scans of Saul's cloak (see Fig. 3, samples MH621_X16, MH621_X23) confirm the presence of an incomplete smalt-rich top paint layer applied on top of red lake glazes (see arrows in ultraviolet image, Fig. 3c). Here the smalt remains are covered by thick layers of strongly fluorescent varnish. The partial removal of the smalt paint from Saul's garment and chair is most likely due to a misinterpretation, where a restorer mistakenly removed the discolored and darkened smalt layer in order to recover the bright red color of Saul's cloak. 

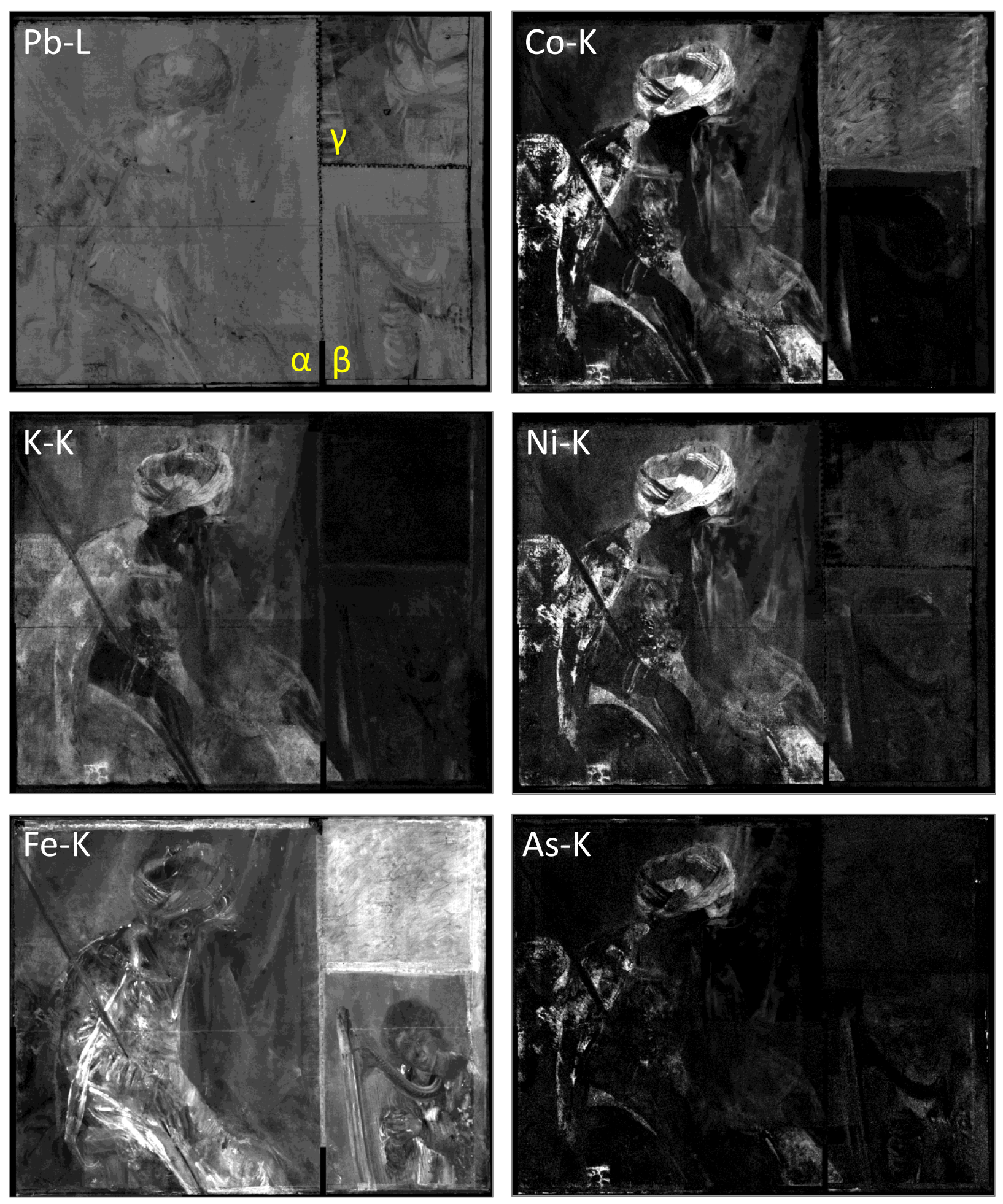

Fig. 2. XRF scanning distribution maps ( $1656 \times 1311$ pixels) of various elements present in the painting. 

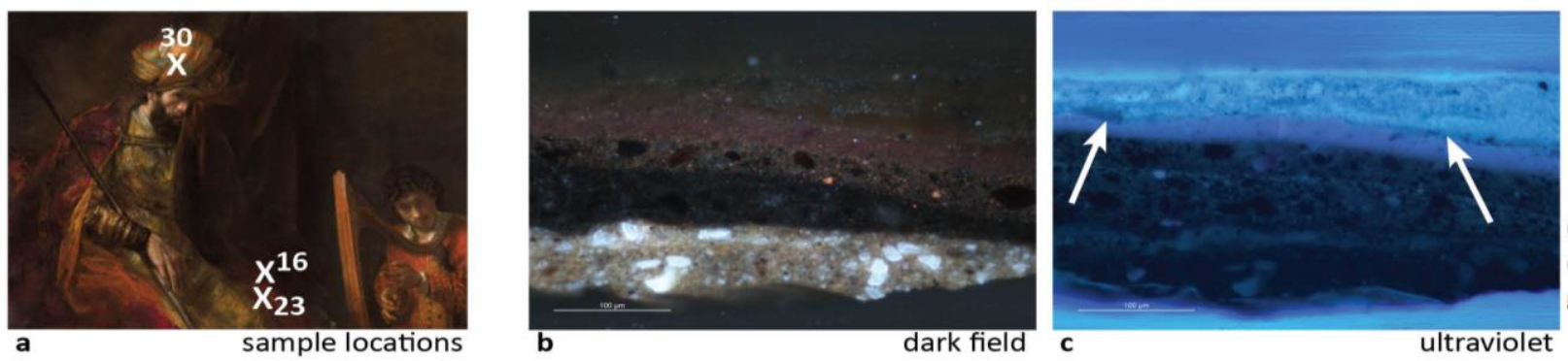

$621 \times 16$ curtain/ garment
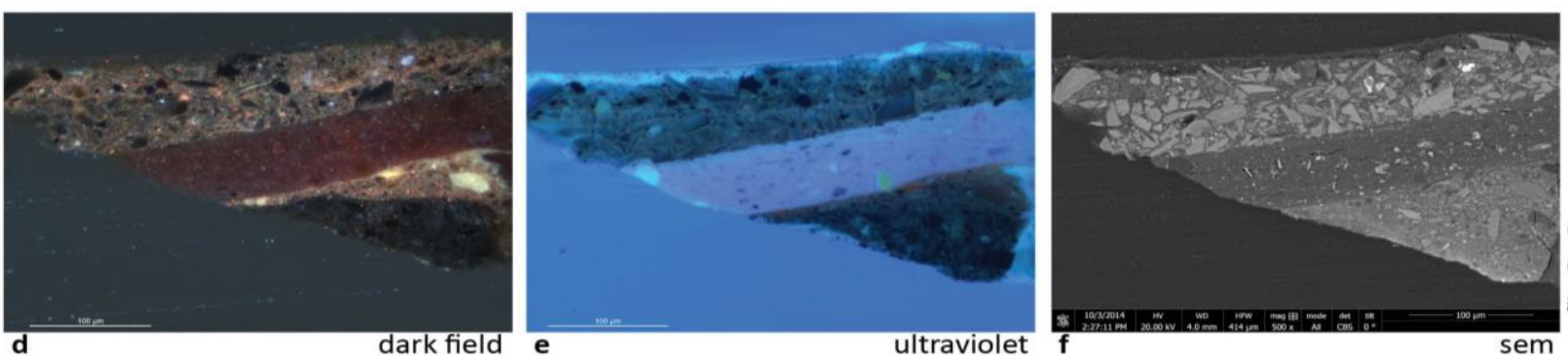

$621 \_x 23$

curtain/ garment
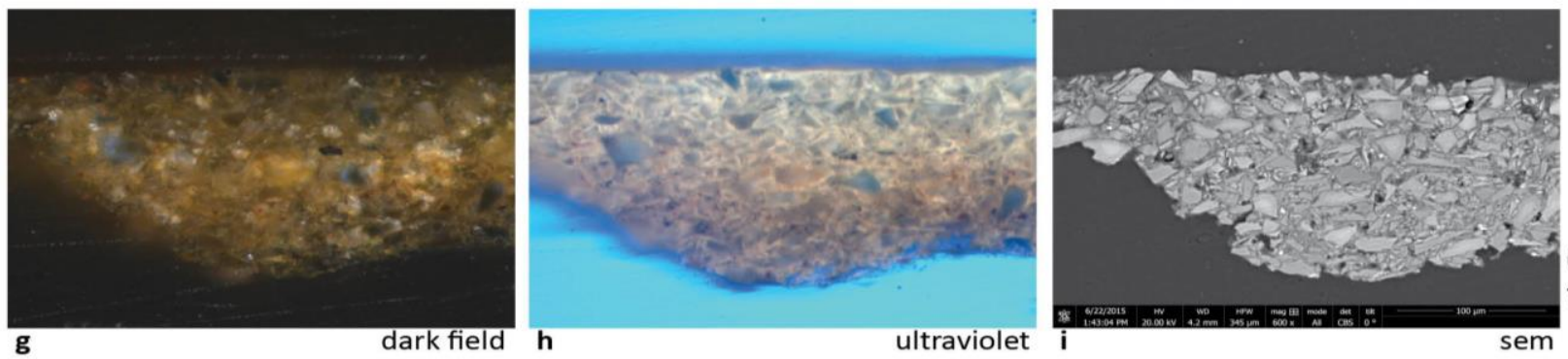

Fig. 3. Optical and backscatter electron (BSE) micrographs of three paint cross sections (MH621_x16, MH621_x23 and MH621_x30) and their locations in the painting (a). Dark field (b, $d, g)$ and ultraviolet fluorescence optical microscopy images (c, e, h) are shown. For samples MH621_x23 and MH621_x30 the BSE images ( $f$, i) highlight the difference in stratigraphy between the turban area (sample M621_x30, single smalt layer, c. $200 \mu \mathrm{m}$ thick) and the cloak area (sample MH621_x23, multiple layers, the top one containing smalt, c. $70 \mu \mathrm{m}$ thick). Scale bar: $100 \mu \mathrm{m}$.

[to editor/typesetter: this should be illustrated large enough so that the scale bars are legible] 
In Fig. 4 a number of Co:Ni correlation plots of the painting are presented. Here the observed $\mathrm{XRF}$ intensity $I_{\mathrm{Ni}}(\mathrm{x}, \mathrm{y})$ of the $\mathrm{Ni}-\mathrm{K}$ lines in a particular pixel $(\mathrm{x}, \mathrm{y})$ is plotted against the corresponding $\mathrm{Co}-\mathrm{K}$ intensity $I_{\mathrm{C}_{0}}(\mathrm{x}, \mathrm{y})$. The rationale behind the choice of $\mathrm{Co}$ : Ni correlation plots over, for instance, Co:As, is that Co-K and Ni-K lines are in the same energy range, and are expected to respond in a similar way with regard to absorption effects. It is clear from Fig. 2 that both the $\mathrm{Co}$ and $\mathrm{Ni}$ images show a meaningful and contrast-rich distribution in which a part of the garment of Saul, his turban, the chair he is sitting on and the curtain he is holding, are visible. On the other hand, the Co:Ni correlation plot of Fig. 4A is fairly noisy. The noise is mainly due to random variations in the observed net $\mathrm{Co}$ and $\mathrm{Ni}$ XRF intensities recorded at all pixel values. This is referred to as counting noise. The average magnitude (i.e., the expectancy value) of the counting noise on an XRF signal $l$ is $I^{1 / 2}$; thus, the relative magnitude of the counting noise is proportional to $I^{1 / 2} / I=I^{-1 / 2}$. It is therefore possible to reduce its relative importance by increasing the recorded intensity $I$. This can be done by using longer dwell times per pixel during the acquisition. However, a relatively important increase in dwell time, say, by an order of magnitude will only result in an improvement in the relative standard deviation (RSD) of the noise by a factor of 3 . An alternative that does not lead to significantly longer acquisition times, however, is to consider scatter plots that are derived from binned MA-XRF maps. By summing the XRF signals from a group of e.g., 4, 9 or 36 pixels together, an XRF spectrum in which the relative magnitude is reduced by a (binning) factor 2,3 or 6 can be obtained. Obviously, in order to obtain binned images that have better signal-to-noise characteristics, their lateral resolution is reduced. The improved signal-to-noise becomes clear when the equivalent Co:Ni scatter plots are considered (Figures $4 \mathrm{~A}-\mathrm{C}$ ). While in the scatter plot derived from the unbinned original data (Fig. $4 \mathrm{~A}$ ) the difference between the groups of pixels having various Co:Ni intensity ratios is difficult to see, in Fig. $4 \mathrm{C}$ this is clearly visible. Next to the "medium Ni" group of pixels (labelled red in Fig. 4DE), a smaller group of pixels (labelled green) is present, characterized by a Ni:Co ratio that is ca $25 \%$ higher than in the large (red labelled)group. Fig. 4 E shows that this "high $\mathrm{Ni}^{\prime \prime}$ group of pixels is situated in Saul's turban and some small parts of his clothing. The "medium Ni" group of smalt pixels corresponds to patchy areas of paint of uneven thickness that are present in Saul's garment in section $\alpha$ as well as in section $\beta$. The pixels belonging to the curtain area in the background between the figures of Saul and David, generally showing both a low Co and $\mathrm{Ni}$ intensity, were labelled blue. Paint samples from the curtain area show lesser amounts of smalt present in the upper paint layer as compared to samples from the turban and Saul's garment, which explains the relative low $\mathrm{Co}$ and $\mathrm{Ni}$ intensities in the curtain area.

Next to these three groups that contain pixels belonging to the $\alpha$ and $\beta$ sections of painting, a fourth group of pixels, characterized by a very low Ni to Co XRF intensity ratio is also visible in Fig. $4 \mathrm{C}$ (magenta color code). These correspond to the paint used to cover the later added canvas insert $\gamma$; this group was already discussed previously. ${ }^{4}$ Microscopic examination of paint samples taken from section $\gamma$ of the painting demonstrated that in these areas, Co is not present in the form of smalt pigment particles but in a more finely divided state, dispersed through the layer. The Co material was likely added to the $19^{\text {th }}$-century overpaint as drying agent (see Ref. 4, pp. 40, 42, 43). In sections $\alpha$ and $\beta$ however, the Co and Ni are definitely present inside coarsely ground smalt particles. 


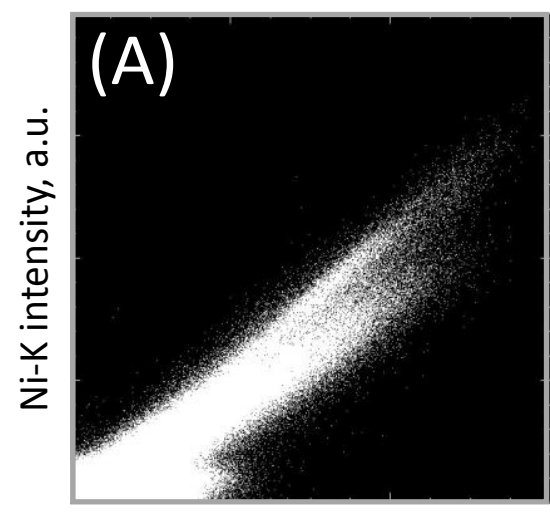

Co-K intensity, a.u.

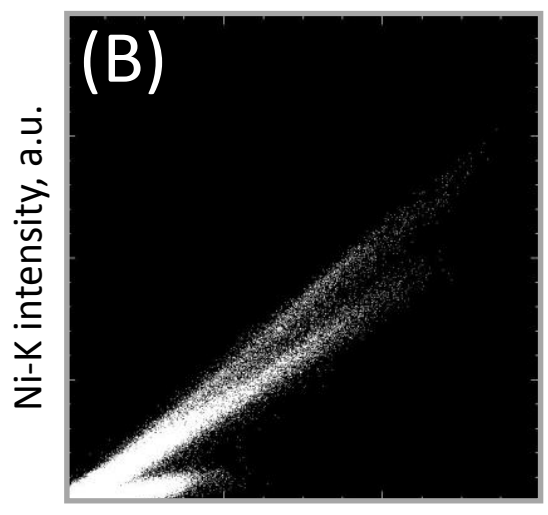

Co-K intensity, a.u.

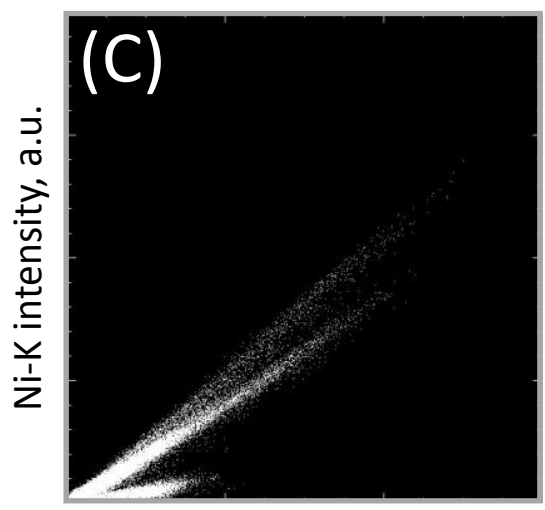

Co-K intensity, a.u.

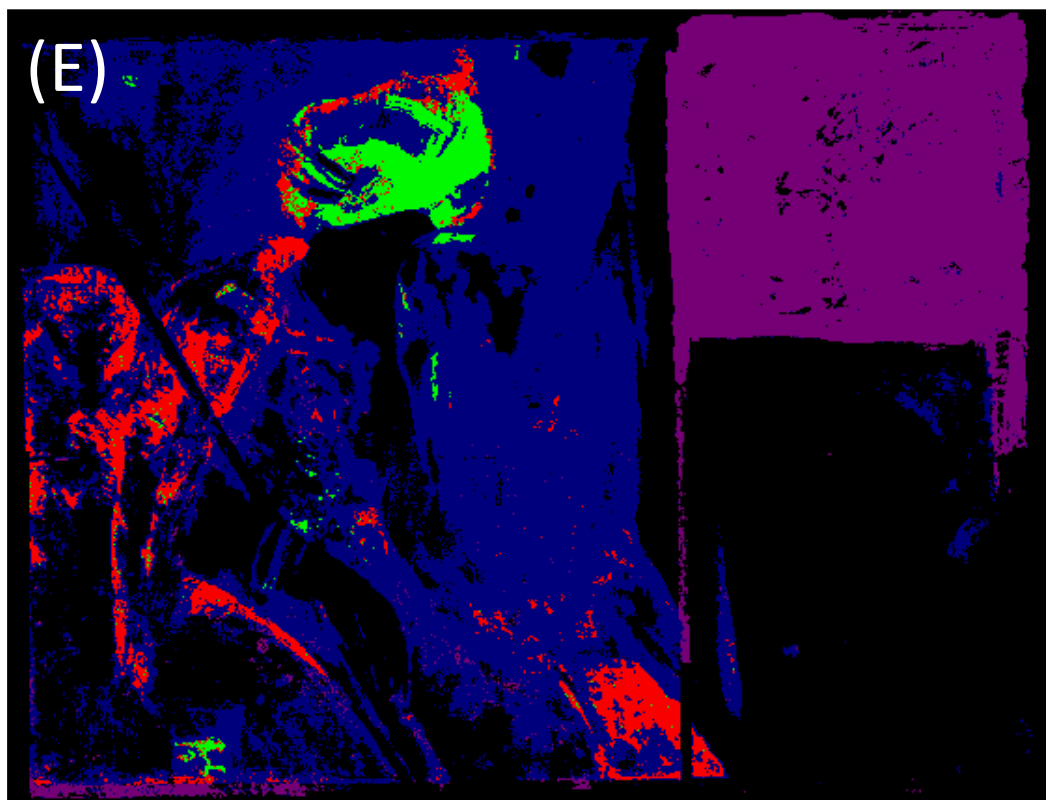

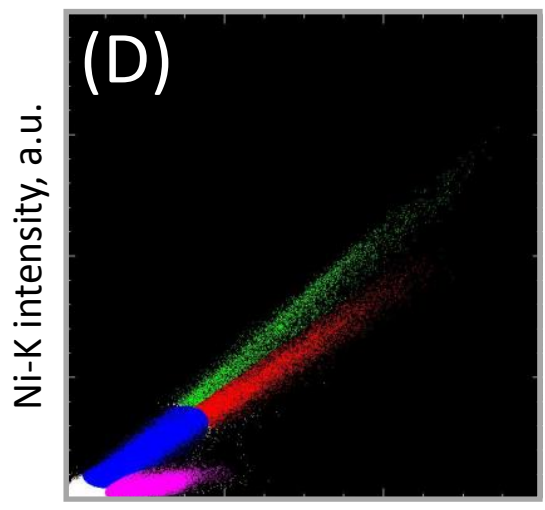

Co-K intensity, a.u.

Fig. 4. Ni-K vs. Co-K XRF intensity scatter plots corresponding to (A) unbinned, (B) $3 \times 3$ and (c) 6x6 binned data; (D) Color coding overlaid on (B); (E) location map of the various pixels groups: Green: 'turban' group; Red: 'garment' pixel group; Blue: 'curtain'/background group; Magenta: 'drier' group. [The uncolored (white) pixels in (D) are shown in black in (E).]. X-ray intensity range of (A-C): o-60oo counts for Co-K; 0-2000 counts for Ni-K.

\subsection{Quantitative smalt particle sample analysis}

In order to verify that the difference between the red and green pixel groups established via the scatter plots of Fig. 4 can effectively be attributed to two types of smalt with a distinguishable composition and not to measurement artifacts or other causes, quantitative SEM-EDX was performed on a number of individual smalt particles. In Fig. 5, backscattered electron (BSE) images of the two examined paint cross-sections are shown. One paint sample originates from the central part of the turban area (MH621_x30, Ni-rich group, green in Fig. 4DE) while the 
second (MH621_X23) was taken from center bottom in Saul's garment (red pixels in Fig. 4DE). In both cross-sections, fairly thick layers (c. 70-200 $\mu \mathrm{m}$ ) of densely packed smalt particles, are present. In all images, the presence of partially leached smalt particles can be discerned. In Table $\mathrm{I}$, the results of quantitative analysis of the two paint samples are summarized. The smalt particles with the highest $\mathrm{K}_{2} \mathrm{O}$ content (10-16\%) are essentially unaltered; similar levels were determined by Spring et al. ${ }^{16}$ in various $16-17^{\text {th }}$ century paintings by artists such as P. Breughel the Elder, J. Beukelaer and T. Gainsborough. In the other particles from both sampling locations, substantial leaching of $\mathrm{K}$ has taken place. In each sample, a series of 14 individual smalt particles were analysed with SEM-EDX. Where partially leached smalt particles were identified (see arrows in Fig. 5), care was taken to limit the irradiated area to their unleached, $\mathrm{K}$-rich centre. However, since the sampling depth of the $\mathrm{X}$-ray signal is more extensive than that of the secondary or backscattered electrons, it is not possible to completely eliminate the irradiation of leached areas of the particles. Within the list of recorded EDX spectra, also a number of spectra were intentionally recorded from the leached-out rims of the pigment grains in order to estimate to what extent the $\mathrm{K}_{2} \mathrm{O}$-content of the particles decreased and to observe the effect on the $\mathrm{NiO}: \mathrm{CoO}$ ratio. From the data in Table I we can infer that:

(a) consistent with the literature on this phenomenon (see, for example. Ref. 27), the leaching process significantly decreases the $\mathrm{K}_{2} \mathrm{O}$ content of the glass, typically from a level of $10-16 \mathrm{wt} \%$ to $2-5 \mathrm{wt} \%$.

(b) the leaching phenomenon does not seem to have a large effect on the observed NiO:CoO concentration ratio. It is therefore valid to statistically compare both sets of spectra, regardless of the leaching condition of the corresponding glass/smalt particles. A two tailed t-test performed on the entire data set $(n=14)$ shows the two average NiO:CoO ratios to be significantly different at the $99 \%$ confidence level.

(c) When only the spectral data are considered that were obtained from unleached smalt particles (i.e., with $\mathrm{K}_{2} \mathrm{O}$-concentration above $10 \%$ ), the 'turban area' particles (sample location $\mathrm{MH621} \times 30$ ) on average show a mean $\mathrm{NiO}: \mathrm{CoO}$ concentration ratio of $0.35 \pm 0.06$ (1s) that is significantly higher than the average ratio of the particles in the 'garment area' (sample location MH621_x23) where it is $0.28 \pm 0.07$. This observation is consistent with the scatter plots of Fig. 4 , were in the turban area, a Ni:Co intensity ratio that is c. $25 \%$ higher than that in the garment area is observed. Of course, among the particles within each group, a certain variation of this ratio is noted, but this is not so high as to obscure the difference among both samples.

When looking at the $\mathrm{CoO}$ wt\% levels in Table 1, it is noted that for the 'turban' sample these levels are fairly consistent $(3.6 \pm 0.3 \mathrm{wt} \%)$. Also the levels are relatively high for a smalt of that period. ${ }^{28}$ This points to a high quality blue smalt. The turban paint consists of almost pure smalt with very small additions of red and yellow earth pigment, and must have been originally blue (now the area has a patchy greenish appearance, typical of degraded smalt). In contrast, the $\mathrm{CoO}$ levels of the smalt particles in the 'garment' sample show a higher variation and lower average $(2.4 \pm 1.0 \mathrm{wt} \%)$. This suggests that a lower quality smalt was used during the second 
stage of the painting process. Here, the smalt was also mixed with fine red earth, a little organic yellow lake, and some dark brown and black particles, and may have been used to give bulk and texture to the glaze-like paint, in addition to coloristic effects.

Spring previously identified the use of two different types of smalt using quantitative EDX analysis of paint cross-sections. ${ }^{28}$ More recently she distinguished two different types of smalt in Rembrandt's Frederik Rihel on Horseback from 1663 (National Gallery, London); the different types are associated with two different phases in the painting process. ${ }^{29}$

Table I. Quantitative SEM-EDX analysis data, derived from two series of 14 smalt particles, originating from two relevant locations on the painting considered to contain different smalt pigments. The average and standard deviation of the $\mathrm{NiO}$ to $\mathrm{CoO}$ concentration ratio for the entire lists and for the leached (italics) and un-leached (bold) particles were calculated separately.

\begin{tabular}{|c|c|c|c|c|c|c|c|c|c|}
\hline \multicolumn{5}{|c|}{ Sample location MH621_x30 - Turban } & \multicolumn{5}{|c|}{ Sample location MH621_x23 - Garment } \\
\hline $\begin{array}{c}\text { particle } \\
\text { nr. }\end{array}$ & $\begin{array}{l}\mathrm{K}_{2} \mathrm{O} \\
\mathrm{wt} \%\end{array}$ & $\begin{array}{l}\mathrm{CoO} \\
\mathrm{wt} \%\end{array}$ & $\begin{array}{l}\mathrm{NiO} \\
\mathrm{wt} \%\end{array}$ & $\mathrm{NiO} / \mathrm{CoO}$ & $\begin{array}{c}\text { particle } \\
\text { nr. }\end{array}$ & $\begin{array}{l}\mathrm{K}_{2} \mathrm{O} \\
\mathrm{wt} \%\end{array}$ & $\begin{array}{l}\mathrm{CoO} \\
\mathrm{wt} \%\end{array}$ & $\begin{array}{l}\mathrm{NiO} \\
\mathrm{wt} \%\end{array}$ & $\mathrm{NiO} / \mathrm{CoO}$ \\
\hline 1 & 14.1 & 3.9 & 1.5 & 0.39 & 1 & 14.5 & 2.7 & 0.4 & 0.14 \\
\hline 2 & 8.1 & 4.1 & 1.4 & 0.34 & 2 & 14.0 & 4.1 & 0.9 & 0.23 \\
\hline 3 & 12.9 & 3.9 & 1.1 & 0.29 & 3 & 9.2 & 4.8 & 0.7 & 0.15 \\
\hline 4 & 3.0 & 4.7 & 1.1 & 0.22 & 4 & 1.3 & 3.2 & 0.7 & 0.22 \\
\hline 5 & 10.0 & 3.2 & 1.2 & 0.36 & 5 & 2.2 & 2.0 & 0.4 & 0.17 \\
\hline 6 & 14.6 & 3.8 & 1.3 & 0.35 & 6 & 13.5 & 1.9 & 0.6 & 0.30 \\
\hline 7 & 15.2 & 3.2 & 1.4 & 0.45 & 7 & 13.5 & 1.9 & 0.6 & 0.30 \\
\hline 8 & 4.1 & 4.7 & 1.6 & 0.35 & 8 & 12.6 & 3.2 & 1.1 & 0.35 \\
\hline 9 & 5.4 & 3.7 & 1.1 & 0.29 & 9 & 2.6 & 4.4 & 1.0 & 0.24 \\
\hline 10 & 3.1 & 4.2 & 1.2 & 0.29 & 10 & 7.7 & 2.3 & 0.8 & 0.34 \\
\hline 11 & 12.3 & 3.6 & 1.0 & 0.28 & 11 & 16.4 & 0.6 & 0.2 & 0.33 \\
\hline 12 & 4.0 & 4.7 & 1.5 & 0.32 & 12 & 14.2 & 2.6 & 0.8 & 0.31 \\
\hline 13 & 3.3 & 3.1 & 1.1 & 0.36 & 13 & 5.7 & 3.9 & 1.1 & 0.28 \\
\hline 14 & 4.0 & 4.0 & 1.4 & 0.34 & 14 & 6.3 & 3.8 & 1.1 & 0.27 \\
\hline \multirow{2}{*}{\multicolumn{4}{|c|}{$\begin{array}{c}\text { Average } \mathrm{NiO} / \mathrm{CoO} \text { ratio overall } \\
\text { Standard deviation }(n=14)\end{array}$}} & 0.33 & \multirow{2}{*}{\multicolumn{4}{|c|}{$\begin{array}{c}\text { Average } \mathrm{NiO} / \mathrm{CoO} \text { ratio overall } \\
\text { Standard deviation }(n=14)\end{array}$}} & 0.26 \\
\hline & & & & 0.06 & & & & & 0.07 \\
\hline \multicolumn{4}{|c|}{ Average $\mathrm{NiO} / \mathrm{CoO}$ for $\mathrm{K}_{2} \mathrm{O} \geq 10 \%$} & 0.35 & \multicolumn{4}{|c|}{ Average $\mathrm{NiO} / \mathrm{CoO}$ for $\mathrm{K}_{2} \mathrm{O} \geq 10 \%$} & 0.28 \\
\hline \multicolumn{4}{|c|}{ Standard deviation $(n=6)$} & 0.06 & \multicolumn{4}{|c|}{ Standard deviation $(n=6)$} & 0.07 \\
\hline \multirow{2}{*}{\multicolumn{4}{|c|}{$\begin{array}{c}\text { Average } \mathrm{NiO} / \mathrm{CoO} \text { for } \mathrm{K}_{2} \mathrm{O}<10 \% \mathrm{w} / \mathrm{w} \\
\text { Standard deviation }(n=8)\end{array}$}} & 0.31 & \multirow{2}{*}{\multicolumn{4}{|c|}{$\begin{array}{c}\text { Average } \mathrm{NiO} / \mathrm{CoO} \text { for } \mathrm{K}_{2} \mathrm{O}<10 \% \mathrm{w} / \mathrm{w} \\
\text { Standard deviation }(n=8)\end{array}$}} & 0.24 \\
\hline & & & & 0.04 & & & & & 0.06 \\
\hline
\end{tabular}


$621 \_\times 23$ curtain/garment
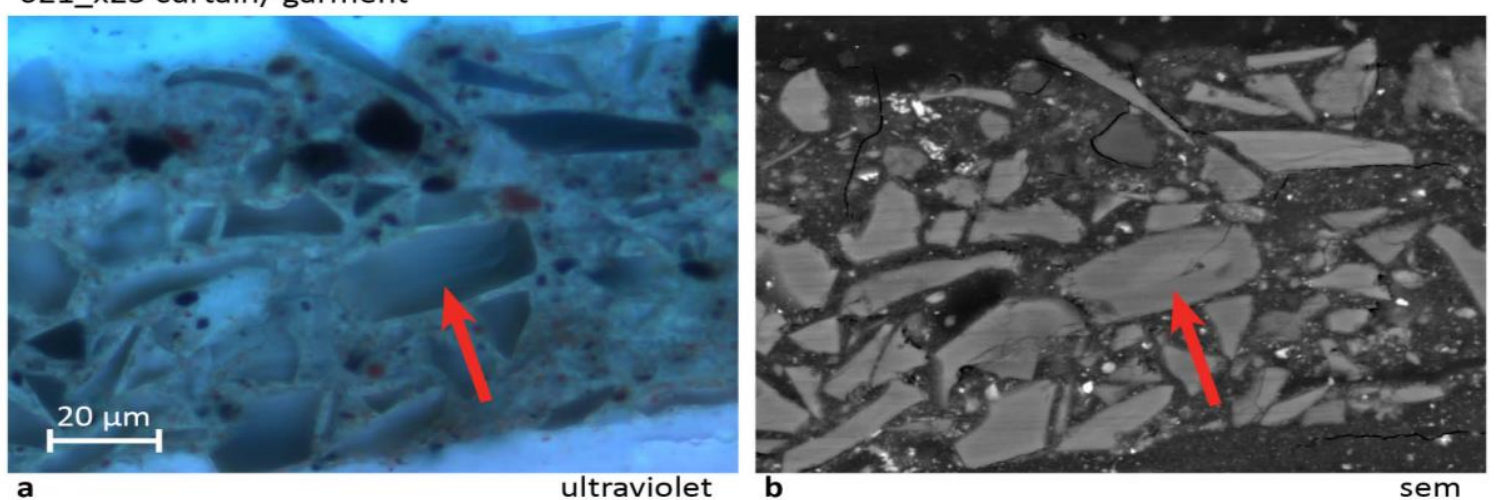

\section{1_x30 turban}

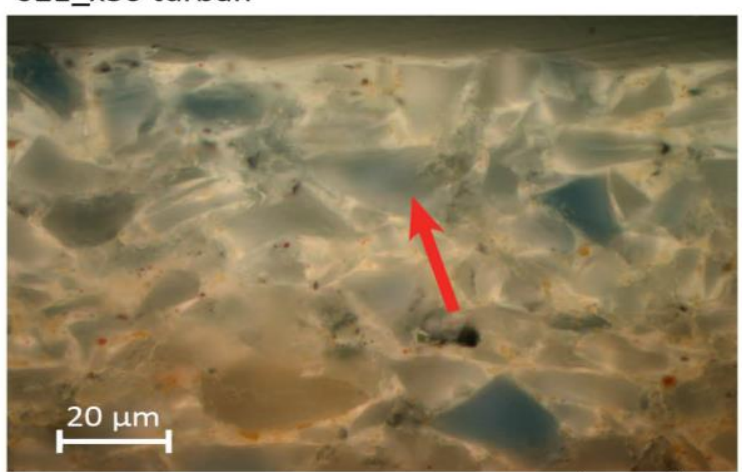

c

ultraviolet

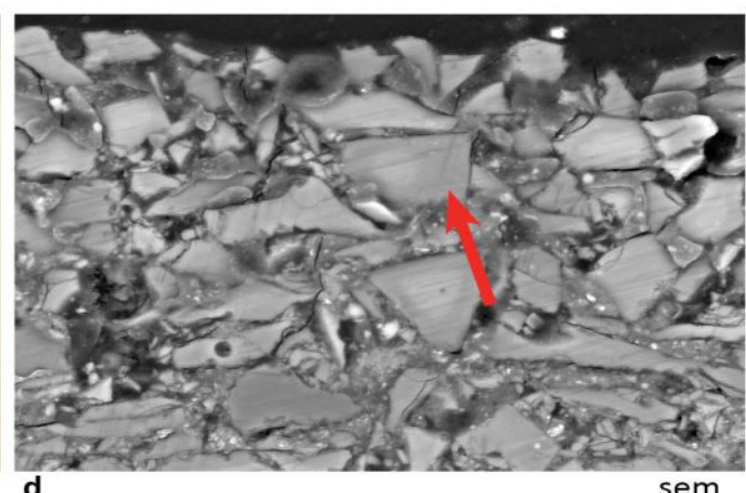

Fig. 5. Optical $(a, c)$ and BSE (b, d) micrographs of samples MH621_x23 (garment) and MH621_x30 (turban) showing compact layers of smalt particles. The sample from the turban consists of almost pure smalt with very small additions of red and yellow earth pigments. In the reworking of Saul's garments the smalt was also mixed with fine red earth, a little organic yellow lake, and some dark brown and black particles. Arrows indicate a few of the partially leached smalt particles showing dark rims. 


\subsection{Hyperspectral Diffuse Reflectance Imaging}

Diffuse reflectance imaging spectroscopy can be used to separate and identify many artist pigments by virtue of their unique electronic transitions and vibrational features in the visible to reflective near infrared ( 400 to $2500 \mathrm{~nm}$ ). 30,31,32 When combined with MA-XRF scanning results, a more complete identification and mapping of artist materials is possible. 33 Here we used hyperspectral RIS imaging to collect image cubes of Saul and David in a partially cleaned state (region in Fig. 6A) in order to collect information related to the distribution of Co, $\mathrm{Ni}$ and $\mathrm{As}$ in the XRF maps. Smalt has strong electronic transitions in the NIR that can be used for mapping by RIS, more specifically the sharp rise in reflectance at $\sim 690 \mathrm{~nm}$ and the broad absorption between $\sim 1200 \mathrm{~nm}$ to $2000 \mathrm{~nm} .{ }^{30}$ The resulting distribution of smalt (Fig. 6B, see the turban and the garment) overlaps with the Co-K XRF map (Fig. 6C) but not all of the elemental Co can be seen in the RIS smalt map. In particular, the part of the turban going from the left brow to the top right of the turban is very prominent in the MA-XRF Co map, but only partially present in the RIS map. Moreover, only the map of the Ni-richer smalt found in Saul's turban matches well with the smalt mapped by the RIS technique. As determined from the cross-sectional analysis (see above), these areas correspond to paints having thick layers of smalt while other pigments (such as iron ochers and black pigments) are present at significantly lower levels. Thus it can be concluded that, compared to the other areas where elemental Co is found by XRF, these Niricher areas have, or had, an optical appearance closer in color to that of blue smalt.
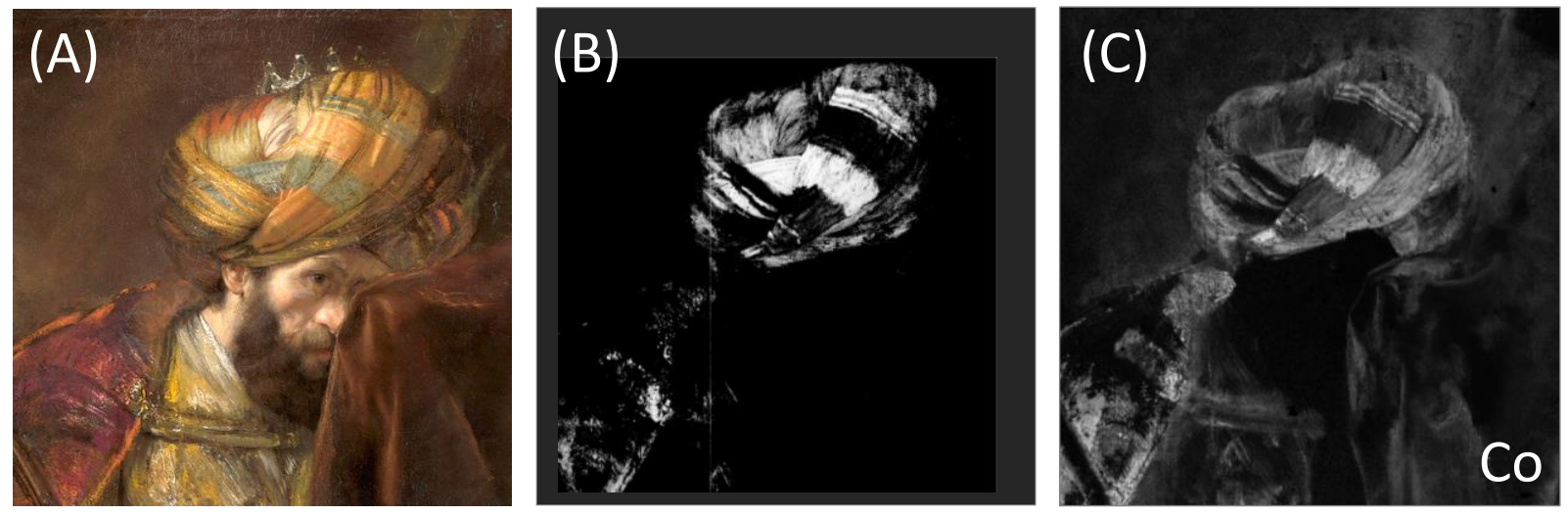

Fig. 6. Detail of Saul/turban area of the painting (A) Visible light image (B) Threshold (0.5 to 1.0 confidence) normalized cross-correlation map of smalt with a diffuse reflectance spectrum from the RIS cube; (C) MA-XRF Co-K map. 


\section{Conclusions}

We have demonstrated that in the painting Saul and David, Rembrandt made use of two distinct types of smalt. A first type, characterized by a NiO:CoO ratio of around 1:3 was employed to paint the broad bluish stripes of the brightly colored turban in the first phase of the painting. The second type of smalt, poorer in $\mathrm{Ni}$ (with a NiO:CoO ratio of around 1:4) and possibly of lesser quality than the first, was part of a thickly applied translucent paint that was employed by the painter in a broad, experimental manner to create textural and coloristic effects in Saul's garments. The results obtained by MA-XRF scanning and SEM-EDX on a limited number of paint samples were found to be consistent with each other.

The identification of smalt-rich layers that contain small amounts of earth pigments and organic lakes in this painting is consistent with that found in other Rembrandt pictures. These results not only support the re-attribution of the painting to Rembrandt and the idea that the picture was painted in two phases, but also that the second phase was painted by Rembrandt as well. It is interesting to note that another painting Frederick Rihel on Horseback (of which Rembrandt's authorship has never been questioned) was also painted in two phases from 1663 (National Gallery London, UK); here, recently two types of smalt were also identified. ${ }^{29}$ In the Rihel painting the different types of smalt were identified using quantitative SEM-EDX analysis of paint cross-sections, ${ }^{28}$ however, to the best of our knowledge, this is the first time that such a distinction has been observed in a $17^{\text {th }}$-century painting using non-destructive imaging techniques. For the Saul and David painting, it can also be noted that there does not appear to be a relation between the (minor) element pattern of the smalt and its degradation behavior.

\section{Acknowledgements}

This research is part of the ReVisualising late Rembrandt: Developing and Applying New Imaging Techniques research project, supported by the Science 4 Arts research program of the Netherlands Organization for Scientific Research (NWO, The Hague, NL) and the National Science Foundation (NSF, Washington DC, USA, award 1041827). We would like to thank colleagues of the Mauritshuis (The Hague, NL) and the Dutch Cultural Heritage Agency (RCE) in Rijswijk, NL for their support and assistance during the scanning of the Saul and David painting. The Fund Baillet Latour (Brussels, B) is acknowledged for financial support to GvdS and KJ. We also like to acknowledge the help of Eliza Longhini and Stijn Legrand during some of the XRF scanning stages. 


\section{References}

${ }^{1}$ Gordenker E.S., Noble P., "Rembrandt's 'Saul and David' at the Mauritshuis: A Progress Report". J. Hist. Netherlandish Art, 2013. 5: 2, DOI:10.5092/jhna.2013.5.2.11.

${ }^{2}$ Weber, Gregor J. M. "Rembrandt Untertan." Kroniek van het Rembrandthuis (2011): 70-75.

3 Noble, P., Van Loon, A., Johnson, C.R., Johnson, D.H., 'Technical investigation of Rembrandt and/or Studio of Saul and David from the collection of the Mauritshuis', in ICOM Committee for Conservation, $16^{\text {th }}$ Triennial Meeting, Lisbon, 26-30 September 2011: Preprints, ed. J. Bridgland, Critério - Produção Gráfica Lda, Almada (Paper 1316, CD-ROM).

${ }^{4}$ Noble P., van Loon A., Alfeld A., Janssens K., Dik J., "Rembrandt and/or studio: Saul and David, C 1655: visualizing the curtain using cross-section analysis and X-ray fluorescence imaging", in: Rembrandt: approches scientifiques et restaurations. Techné, 2012, 35, 36-45.

5 Van de Wetering E. (with the collaboration of Carin van Nes and translated and edited by Murray Pearson) "Rembrandt's Paintings Revisited: A Complete Survey". Dordrecht: Springer, 2014. ISBN 978-94-017-9173-1.

${ }^{6}$ InFocus Mauritshuis: Rembrandt?, 2015/28: nr 2.

7 Bredius A., Gerson H., 1969, "Rembrandt: The Complete Edition of the Paintings". London: Phaidon Press, 1971.

8 Schwartz G., 1985, "Rembrandt: his life, his paintings". New York: Viking Press, 1985.

9 De Vries et al. proposed that the painting was started in the mid-1650s and finished in the mid-166os. Recently Van de Wetering published a date of c. 1646 and 1652 , while the Mauritshuis regards the first phase was painted in or around 1650 and the second phase in the mid-1650s. InFocus Mauritshuis: Rembrandt?, 2015/28: nr 2, 10, 19.

${ }^{10}$ It is still doubted by some scholars as to whether the second stage was painted by Rembrandt, or if one of his assistants or pupils could have completed the work.

${ }_{11}$ Paschinger H., Richard H., 1995, "Blaupigmente der Renaissance und Barockzeit in Österreich", Naturwissenschaften in Der Kunst, Böhlau Verlag, Vienna, pp. 63-66.

12 Van Loon, A., Noble, P., Boon, J.J. 2011. White hazes and surface crusts in Rembrandt's Homer and related paintings. Preprints ICOM Committee for Conservation 16th Triennial Meeting, Lisbon, 19-23 September 2011, ed. J. Bridgland, Critério - Produção Gráfica Lda, Almada (CD-Rom). Ashok Roy, 'Studying Rembrandt's Techniques at the National Gallery, London', Rembrandt: approches scientifiques et restaurations. Technè 35, 2012, 11.

${ }^{13}$ M. Alfeld, M. Wahabzada, C. Bauckhage, K. Kersting, G. Wellenreuther, and G. Falkenberg, "Non-negative factor analysis supporting the interpretation of elemental distribution images acquired by XRF", Journal of Physics: Conference Series 2004. 499: 012013.

14 Robinet L., Spring M., Pagès-Camagna S., "Vibrational spectroscopy correlated with elemental analysis for the investigation of smalt pigment and its alteration in paintings". Anal. Methods, 2013. 5: 4628-4638.

15 Stege $H_{\text {., }}$ "Out of the blue? Considerations of the early use of smalt as blue pigment in European easel painting.", Zeitschrift für Kunsttechnologie u. Konservierung 2004. 18: 121-142. ${ }^{16}$ Spring M., Higgitt C. and Saunders D. "Investigation of pigment-medium interaction processes in oil painting containing degraded smalt.", National Gallery Technical Bulletin 2005. 26: 56-70. 
${ }_{17}$ Terczynskanska-Madej A., Cholewa-Kowawalska K. and Laczka M., "The effect of silicate network modifiers on colour and electron spectra of transition metal ions". Optical Materials, 2010. 32: 1456-1462.

${ }^{18}$ Boon J., Keune K., Van der Weerd J., Geldof M., van Asperen de Boer A., "Imaging Microspectroscopic, Secondary Ion Mass Spectrometric and Electron Microscopic Studies on Discoloured and Partially Discoloured Smalt in Cross-Sections of 16th Century Paintings". Chimia 2001. 55: 952-960.

${ }^{19}$ Altatavilla, C. and Ciliberterto E. 2004. "Decay characterization of glassy pigments: an XPS investigation of smalt paint layers". Applied Physics 2004. A79: 309-314.

${ }^{20}$ Robinet L., Spring M., Pagès-Camagna S., Vantelon D., Trcera N., "Investigation of the Discoloration of Smalt Pigment in Historic Paintings by Micro-X-ray Absorption Spectroscopy at the Co K-Edge", Anal. Chem., 2011. 83: 5145-5152.

${ }^{21}$ Alfeld M., Janssens K., Dik J., de Nolf W., van der Snickt G., 2011, "Optimization of mobile scanning macro-XRF systems for the in situ investigation of historical paintings", J. Anal. At. Spectrom. 2012, 26, 899-909.

${ }^{22}$ Alfeld M., Pedroso J.V., van Eikema Hommes M., Van der Snickt G., Tauber G., Blaas J., Haschke M., Erler K., Dik J., Janssens K., "A mobile instrument for in situ scanning macro-XRF investigation of historical paintings". J. Anal. At. Spectrom., 2013, 28, 760-767.

${ }^{23}$ Alfeld M., Janssens K., "Strategies for processing mega-pixel X-ray fluorescence hyperspectral data: a case study on a version of Caravaggio's painting Supper at Emmaus". J. Anal. At. Spectrom. 2015, 30, 777-789.

${ }^{24}$ Solé V, Papillon E., Cotte M., Walter P., Susini J., "A multiplatform code for the analysis of energy-dispersive X-ray fluorescence spectra", Spectrochimica Acta B, 2007. 62, 63-68.

${ }^{25}$ Van Loon, A., Keune, K., Boon, J.J., 2005, "Improving the surface quality of paint crosssections for imaging analytical studies with specular reflection FTIR and static-SIMS", in Proceedings of Art'o5 Conference on Non-destructive Testing and Microanalysis for the Diagnostics and Conservation of the Cultural and Environmental Heritage Lecce (Italy) 15-19 May 2005 (CD-ROM).

${ }^{26} \mathrm{~K}$ associated with the use of red lake pigment was observed earlier in the $\mathrm{K}$ distribution maps of the 1669 Rembrandt Self-Portrait (Mauritshuis). No smalt was used in that painting. See Noble, P., Van Loon, A., Van der Snickt, G., Janssens, K., Alfeld, M., Dik, J. 2014, 'The development of new imaging techniques for the study and interpretation of late Rembrandt paintings', in Preprints ICOM Committee for Conservation 17th Triennial Meeting, Melbourne, 1519 September 2014.

${ }^{27}$ Melcher M. and Schreiner M., "Glass Degradation by Liquids and Atmospheric Agents". In: K. Janssens, editor. Modern Methods for Analysing Archeological and Historical Glass. Chichester UK: John Wiley and Sons, 2013.'

${ }^{28}$ Spring M., Bean S., "Quantitative EDX analysis of smalt pigment in the variable pressure", SEM2010 Conference, British Museum, London, UK: Archetype Publications, 2011.

${ }^{29}$ Spring M., "Pale grey or deep blue? Evaluating smalt in Rembrandt's paintings", talk at 'Rembrandt Now: Technical Practice, Conservation and Research' Symposium, November 1315, 2014, National Gallery London (forthcoming).

${ }^{30}$ Bacci M. and Picollo M., "Non-destructive detection of $\mathrm{Co}(\mathrm{II})$ in paintings and glasses", Studies in Conservation, 1996, 41, 136-144. 
${ }^{31}$ Bacci M., Picollo M., Trumpy G., Tsukada M. and Kunzelman D., "Non-invasive identification of white pigments on 2oth century oil paintings by using fiber optic reflectance spectroscopy", Journal of the American Institute for Conservation, 2007, 46, 27-37.

${ }^{32}$ Delaney J.K., Zeibel J.G., Thoury M., Littleton R., Palmer M., Morales K.M., de La Rie E.R., Hoenigswald A., "Visible and infrared imaging spectroscopy of Picasso's Harlequin musician: mapping and identification of artist materials in situ", Appl. Spectroscopy 2010, 64, 584-586. ${ }^{33}$ Dooley K.A., Conover, D.M., Glinsman L.D., Delaney J.K., "Complementary Standoff Chemical Imaging to Map and Identify Artist Materials in an Early Italian Renaissance Panel Painting", Angewandte Chemie Int. Ed. 2014, 53, 13775-13779. 